\title{
KEBIJAKAN EKONOMI PADA MASA KHULAFAURASYIDIN
}

\author{
Oleh: \\ Nurul Wahida Aprilya (90100118110)
}

Fakultas Ekonomi dan Bisnis Islam UIN Alauddin Makassar

e-mail:wahidaprilya@gmail.com

Ilmu ekonomi islam ini telah muncul pada tahun 1970-an, tetapi pemikiran mengenai ekonomi islam telah muncul pada masa Nabi Muhammad SAW. Ekonomi islam ini muncul bersamaan dengan diturunkannya Al-Qur'an serta masa kehidupan Rasulullah pada abad 6M sampai abad 7M ${ }^{1}$. Pada masa kepemimpinan Rasulullah SAW tepatnya pada periode Madinah, perekonomian islam telah terbangun walaupun konsepnya masih tebilang sangat sederhana, tetapi beliau telah mampu menujukkan bahwa prinsip-prinsip yang mendasar bagi pengelolaan ekonomi ${ }^{2}$. Praktik ekonomi islam pada masa Rasulullah dan Khulafaurrasyidin serta tab'in menunjukkan adanya peranan pasar yang sangat besar. Rasulullah SAW sangat menghargai harga yang dibentuk oleh mekanisme pasar sebagai harga yang adil. Harga yang adil dapat tercipta dipasar bila adanya moralitas, kejujuran, keterbukaan dan keadilan³ ${ }^{3}$ Pada abad ketujuh, Rasulullah pertama kali memperkenalkan konsep baru pada dibidang keuangan. Semua hasil penghimpunan negara harus dikumpulakn terlebih dahulu dan kemudian dikeluarkan sesuai dengan kebutuhan negara. Tempat pusat pengumpulan dana disebut dengan Bai al mal. Pada masa pemerintahan Rasulullah SAW, bai al mal terletak di Masjid Nabawi yang ketika itu digunakan sebagai kantor pusat negara yang seklaigus berfungsi sebagai

${ }^{1}$ Pusat Pengkajian dan Pengembangan Ekonomi Islam, Ekonomi Islam, (Jakarta: Rajawali Press, 2012), h. 97

2 Ibnudin, Pemikiran Ekonomi Islam Pada Masa Nabi Muhammah, (Jurnal Pendidikan dan Studi Islam, Vol. 5, No. 1, 2019), h. 51-61

${ }^{3}$ Idris Parakkasi dan Kamiruddin, Analisis Harga dan Mekanisme Pasar dalam Perspektif Islam, (Laa Maysir, Vol. 5, No. 1), h. 107-120 
tempat tinnggal Rasulullah $\mathrm{SAW}^{4}$. Asal mula lembaga Baitul Mal yang telah di cetuskan dan difungsikan oleh Rasulullah SAW. dan diteruskan oleh Abu Bakar As-Shiddiq, semakin dikembangkan fungsinya pada masa pemerintahan Khalifah Umar Bin Khattab sehingga menjadi lembaga yang reguler dan permanen. Pembangunan institusi Baitul Mal yang dilengkapi dengan sistem administrasi yang tertata baik dan rapih merupakan kontribusi terbesar yang diberikan oleh khalifah Umar Bin Khattab kepada kaum muslimin ${ }^{5}$. Sumber-sumber pendapatan negara pada masa Rasulullah SAW yaitu berasal dari (Zakat, Khums, Kharaj, Jizyah, dan penerimaan lainnya $)^{6}$.

\section{Kebijakan Ekonomi Pada Masa Rasulullah SAW :}

\section{Kebijakan Moneter}

Pengelolaan sistem moneter pada masa pemerintahan islam diserahkan kepada lembaga Baitul mal. Baitul mal merupakan post yang dikhususkan untuk mengelola semua pemasukan atau pengeluaran harta yang menjadi hak kaum muslimin. Pengelolaan moneter tersebut mengalokasikan dana untuk penyebaran Islam, pendidikan dan kebudayaan, pengembangan ilmu pengetahuan, pengembangan inprastruktur dan penyediaan layanan kesejahteraan sosial. Alokasi dana Baitul mal tersebut mempunyai dampak baik terhadap pertumbuhan ekonomi dan kenaikan Agregate Demand sekaligus

4 Adiwarman Azhar Karim, Sejarah Pemikiran Ekonomi Islam, Edisi 3 (cet. 4; Jakarta: PT. Raja Grafindo Persada, 2010), h. 51-53

5 Mustaring, Eksistensi “Baitul Maal” dan Peranannya dalam Perbaikan Ekonomi Rumah Tangga dalam Era Masyarakat Ekonomi ASEAN. (Jurnal Pemikiran, Penelitian, Ilmu-ilmu Sosial, Hukum dan Pengajarannya. Vol. 11, No. 2), h. 118-128

${ }^{6}$ Ibnudin, Pemikiran Ekonomi Islam Pada Masa Nabi Muhammah, (Jurnal Pendidikan dan Studi Islam, Vol. 5, No. 1, 2019), h. 51-61 
Agregate Supply. Karena populasi akan semakin meningkat dan penggunaan sumber daya alam semakin maksimal ${ }^{7}$.

\section{Kebijakan Fiskal}

Dalam islam, kebijakan fiskal merupakan suatu kewajiban negara dan menjadi hak rakyat. Pembelanjaan pemerintah dalam koridor negara islam berpegang pada terpenuhinya pemuasan semua kebutuhan primer tiap-tiap individu dan kebutuhan sekunder dan luks sesuai kadar kemapuannya sebagai individu yang hidup dalam masyrakat. Dengan penjaminan kebutuhan primer, negara telah membangun suatu insfrastruktur ekonomi dengan distribusi ekonomi yang adil, karena orang-orang kurang memiliki kemampuan dari sisi ekonomi disantuni oleh negara dengan penjaminan pemenuhan kebutuhan-kebutuhan pokoknya ${ }^{8}$

\section{Kebijakan ekonomi pada masa khulafaurasyidin}

\section{Abu Bakar As Shiddiq}

Setelah wafanya Rasulullah SAW, Abu bakar As-Siddiq terpilih menjadi khalifah pertama. Beliau merupakan pemimpin agama sekaligus pemimpin negara kaum muslimin. Dalam pemerintahan Abu Bakar yang hanya berlangsung 2 tahun berjalan dengan baik dengan berhasil mengatasi banyaknya orang yang murtad, nabi palsu, dan pembangkang zakat, maka terjadila perang Riddah. (Perang Melawan Kemurtadan). ${ }^{9}$ Dalam menjalankan pemerintahan dan roda ekonomi masyarakat Madinah Abu Bakar sangat memperhatikan keakuratan perhitungan zakat. Abu Bakar juga mengambil langkah-langkah yang strategis dan tegas untuk mengumpulkan zakat dari semua umat

${ }^{7}$ Hoirul Amri, Kebijakan Moneter Pada Awal Pemerintahan Islam Dalam Pembangunan Perekonomian (Studi Analisis Pada Masa Rasulullah SAW Dan Sahabat), (Muqtashid, Vol. 1, No. 1), h. 9-24

${ }^{8}$ Lilik Rahmawati, Kebijakan Fiskal dalam Islam, (Al-Qanun, Vol. 11. No. 2). h. 436461

9 Mudhiiah, Kharidatul. "Analisis Sejarah Pemikiran Ekonomi Islam Masa Klasik." IQTISHADIA 8.2 (2016). 
Islam termasuk Badui (a'rabi) yang kembali memperlihatkan tanda-tanda pembangkangan membayar zakat sepeninggal Rasulullah saw. Prinsip yang digunakan Abu Bakar dalam mendistribusikan harta baitul mal adalah prinsip kesamarataan, yakni memberikan jumlah yang sama kepada semua sahabat Rasulullah saw.

\section{Umar Bin Khattab}

Umar bin Khattab merupakan pengganti dari Abu Bakar. Pemerintahan Umar bin Khattab dikenal dengan pemerintahan yang berish ditopang dengan karakteristik pribadi yang tegas dan berwibawa sehingga terbentuk kondisi masyarakat yang damai, sejahtera dan makmur ${ }^{10}$. Adapun kebijakan- kebijakan ekonomi pada masa pemerintahan Umar bin Khattab yaitu : Pendirian Lembaga Baitul Mal, Kepemilikan tanah, Ushr (pajak), Sedekah dari Non- Muslim, Membuat mata uang sendiri, mengganti dinar yang berasal dari persia yang selama ini di gunakan.

\section{Utsman Bin Affan}

Usman bin Affan terpilih menjadi khalifah ketiga yang memimpin paling lama selama 12 tahun, namun tidak ada perubahan dalam masa kepemimpinanya. Beliau melanjutkan dan mengambngkan kebijakan kebijakan pada masa pemerintahan yang lalu. Khalifah Utsman bin Affan mengambil suatu langkah kebijakan tidak mengambil upah dari kantornya. Sebaliknya, ia meringankan beban pemerintah dalam hal-hal yang serius, bahkan menyimpan uangnya di bendahara negara. Adapun kebijakan- kebijakan ekonomi pada masa pemerintahnya sebagai berikut: Mengembangkan sistem ekonomi yang telah di praktikan pada masa umar bin kahattab, Membentuk armada laut dan kepolisian di wilayah Mediterania., Tidak mengambil upah dari kantornya, Mempertahankan sistem pemeberian bantuan serta memberikan sejumlah uang kepada masyarakat yang berbedabeda. ${ }^{11}$

\section{Ali bin Abi Thalib}

Dalam pemerintahannya Ali bin Abi Thalib melakukan gebrakan dan kebijakan politik seperti penegakan hukum secara masif, memecat guberur yang melakukan korupsi

${ }^{10}$ Rizal Fahlefi, “KebijakanEkonomi Umar bin Khattab”, JURIS, Vol. 13 ,No. 2, 2014, H.130

11 Mudhiiah, Kharidatul. "ANAlISIS SejArah PemIkIraN ekoNomI ISlAm mASA klASIk." IQTISHADIA 8.2 (2016). 
pada masa Umar bi Affan,mengambil alih tanah yang sudah negara dari keluarga Umar bin Affan dan memfungsikan kembali Baitul Mal. ${ }^{12}$ Di antara kebijakan ekonomi pada masa pemerintahannya, ia menetapkan pajak terhadap para pemilik hutan sebesar 4000 dirham dan mengizinkan Ibnu Abbas, gubernur Kufah, memungut zakat terhadap sayuran segar yang akan digunakan sebagai bumbu masakan. Ada persamaan kebijakan ekonomi pada masa Ali bin Abi Thalib dengan khalifah sebelumnya. Pada masa Ali alokasi pengeluaran kurang lebihmasih tetap sama sebagaimana halnya pada masa pemerintahan Khalifah Umar.

12 Junaidin,. "PEMERINTAHAN ALI BIN ABI THALIB DAN PERMULAAN KONFLIK UMAT ISLAM." FiTUA: Jurnal Studi Islam 1.1 (2020): 33-48. 


\section{DAFTAR PUSTAKA}

Adiwarman, A.K. (2010). Sejarah Pemikiran Ekonomi Islam, Edisi 3 cet. 4; PT. Raja Grafindo Persada, Jakarta.

Amri, H. (2016). Kebijakan Moneter Pada Awal Pemerintahan Islam Dalam Pembangunan Perekonomian (Studi Analisis Pada Masa Rasulullah SAW Dan Sahabat). Muqtashid, 1 (01). 9-24

Fauzan, I. (2019). The The Thingking Of Islamic Economy In Muhammad Prophet Era (Pemikiran Ekonomi Islam Pada Masa Nabi Muhammad. Risalah, Jurnal pendidikan dan Studi Islam, 5 (1, March), 51-61.

JUNAIDIN, J. (2020). PEMERINTAHAN ALI BIN ABI THALIB DAN PERMULAAN KONFLIK UMAT ISLAM. FiTUA: Jurnal Studi Islam, 1(1), 33-48.

Mudhiiah, K. (2016). ANALISIS SEJARAH PEMIKIRAN EKONOMI ISLAM MASA KLASIK. IQTISHADIA, 8(2).

Mustaring, M. (2017), Eksistensi "Baitul Maal" dan Peranannya dalam Perbaikan Ekonomi Rumah Tangga dalam Era Masyarakat Ekonomi ASEAN. Supremasi: Jurnal Pemikiran, Penelitian, Ilmu-ilmu Sosial, Hukum dan Pengajarannya, 11 (2), $118-128$

Parakassi, Idris dan Kamirullah. (2018). Anilisis Harga dan Mekanisme Pasar dalam Perspektif Islam. Laa Maysir, 5(1): 107-120

Pengkajian, pusat dan Pengembangan ekonomi islam (P3EI). (2012). Ekonomi Islam. Jakarta: Rajawali Pers.

Rahmawati, L. (2008). Kebijakan Fiskal dalam Islam, Al-Qanun, 11 (2) h. 436-461 
Fahlefi, R. (2018). Kebijakan Ekonomi Umar Bin Khatthab. JURIS (Jurnal Ilmiah Syariah), 13(2) 